\title{
Strengthening Prestressed Concrete Bridge Girders and Building Beams with Carbon Fiber Reinforced Polymer Sheets
}

\author{
Herish A. Hussein and Zia Razzaq
}

\begin{abstract}
The effect of Carbon Fiber Reinforced Polymer (CFRP) retrofitting and concrete type on the flexural strength of prestressed concrete I-section girders used in bridges and beams in buildings is investigated. Non-linear momentcurvature relationships are predicted using an iterative algorithm for both non-retrofitted and CFRP-retrofitted prestressed concrete girder and beam cross-sections with various concrete types. Two different CFRP-retrofitting schemes are analyzed for comparing their effectiveness. It is found that although non-retrofitted beam section exhibits greater ductility, the use of CFRP retrofitting in both tension and compression regions simultaneously results in a significant increase in flexural strength. It is also found that the higher the ultimate concrete strength, the higher is the influence of CFRPretrofitting on increasing flexural strength.
\end{abstract}

Index Terms - Flexural Strength, CFRP, Retrofitting.

\section{INTRODUCTION}

The use of Carbon fiber reinforced polymer (CFRP) as a retrofitting material in civil engineering projects and studies is gaining impetus. What makes it an attractive material to civil engineers is owing to the facts that it is light, relatively easy to install, is available in practical dimensions, and is non-corrosiveness [1]. Hussein and Razzaq showed that CFRP can help in decreasing deflection for both highway bridge girders [2] and building prestressed beams [3]. Other past studies have shown that the effect of fiber reinforced polymer materials in tension regions of both prestressed and non-prestressed reinforced concrete beams is to increase structural strength [4]-[7]. In this paper, the combined effectiveness of concrete type and CFRP laminar sheets is investigated in increasing the strength of prestressed concrete beams. Two retrofitting strategies are studied as functions of concrete type, namely, the use of CFRP sheets at the bottom surface of the lower flange only, and CFRP sheets installed at the bottom or top surfaces of both flanges.

\section{Problem Statement}

A non-retrofitted prestressed concrete girder and a nonretrofitted prestressed concrete I-beam as shown in Fig. 1(a) and 2(a) are used as baseline girder and beam cross sections, respectively. They both have three rows of ASTM Grade

Published on January 10, 2021.

Herish A. Hussein, Old Dominion University, USA

(e-mail: hhuss001@odu.edu)

Zia Razzaq, Old Dominion University, USA.

(e-mail: zrazzaq@odu.edu)
270 seven-wire strands each having a $1 / 2$ in. diameter, and each row has twelve strands for the girder sections and eight strands for the beam sections. It is assumed that the strands have an elastic-plastic material stress-strain relationship. The concrete used herein has an ultimate compression strength $f_{c}^{\prime}$ and follows the nonlinear stress-strain relation as given below [8]:

$$
f_{c}=f_{c}^{\prime}\left[2\left(\epsilon_{c} / \epsilon_{\circ}\right)-\left(\epsilon_{c} / \epsilon_{\circ}\right)^{2}\right]
$$

where $\epsilon_{\mathrm{o}}$ is the concrete strain at $f_{c}^{\prime}$.
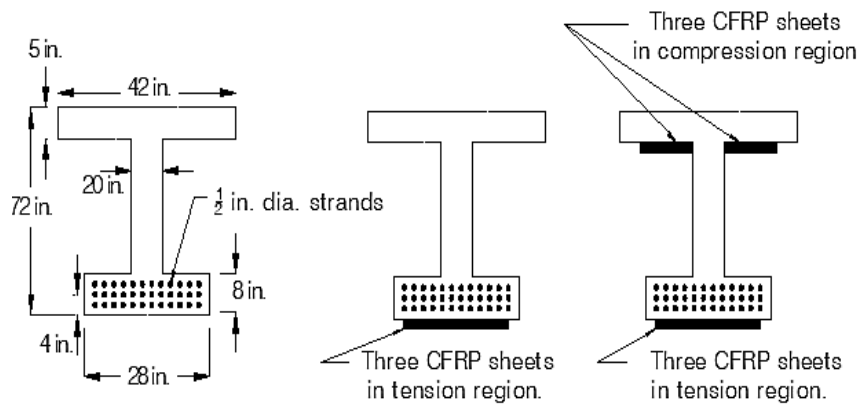

(a)

(b)

(c)

Fig. 1. Prestressed girder sections including CFRP

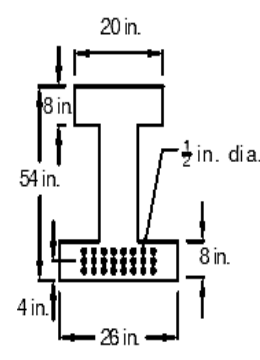

(a)

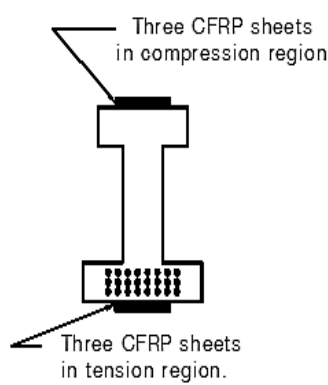

(c)
Fig. 2. Prestressed I-beam sections including CFRP.

Fig. 1(b) and 1(c) show the girder being retrofitted once in tension region only, and then once in both tension and compression regions simultaneously. Fig. 1(b) shows the girder cross section retrofitting scheme in which three CFRP sheets, each of size $26 \times 0.0625$ in., are attached in the tension region only. Fig. 1(c) shows the second scheme in which CFRP sheets are attached in both tension and compression regions simultaneously. The compression region sheets are attached on the underside of the compression flange so that they will not interfere with any overlaid concrete slabs or floors. Three CFRP sheets are mounted to each of the upper girder flange on both the left 
and right sides of the girder web. Each sheet size is $13 \mathrm{x}$ $0.0625 \mathrm{in}$. The same type of retrofitting schemes is repeated to the building beam as shown in Fig. 2, but with different CFRP sheet sizes. On the tension side, three $16.0 \times 0.0625$ in. CFRP sheets are mounted. On the compression side, the same amount of CFRP sheets is installed on the upper side of the flange, $16.0 \times 0.0625 \mathrm{in}$.

The ultimate strength of CFRP in both tension and compression is taken as $260 \mathrm{ksi}$, and its Young's modulus as $22,000 \mathrm{ksi}$. The aim of this study is to generate theoretical moment-curvature relations for each of the three beam cross sections shown in Fig. 1 and Fig. 2 in order to determine the combined effectiveness of the retrofitting strategies with CFRP sheets and the type of concrete used for increasing the ultimate strength of the girder and beam sections.

\section{PREDICTION OF MOMENT-CURVATURE RELATIONS}

The strands used in the girder and the beam provide a tota 8 restress of 160 kips after excluding all of the prestress losses. In Fig. 3, Cc represents concrete compression force, Tps is the prestressing force, TCFRP is the CFRP tension force, and CCFRP is the CFRP compression force. The distance from $\mathrm{Cc}$ to the neutral axis is $\mathrm{X}$. The cross-sectional dimensions b1, b2, c1, c2, and the curvature $\phi$ are also shown in the figure.

The concrete force $\mathrm{Cc}$ and its distance $\mathrm{X}$ from the neutral axis are determined using the following expressions [8]:

$$
\begin{aligned}
& \mathrm{C}_{\mathrm{c}}=\mathrm{C}_{\mathrm{c} 2}-\mathrm{C}_{\mathrm{c} 1}=\mathrm{b}_{2} \times c_{2}^{2} \times f_{c}^{\prime} \times \frac{\phi}{\epsilon_{\mathrm{o}}}\left(1-\frac{\phi \times c_{2}}{3 \epsilon_{\mathrm{o}}}\right)- \\
& \mathrm{b}_{1} \times c_{1}^{2} \times f_{c}^{\prime} \times \frac{\phi}{\epsilon_{\mathrm{o}}}\left(1-\frac{\phi \times c_{1}}{3 \epsilon_{\circ}}\right)(2) \\
& \mathrm{X}=\left\{\left[\mathrm{C}_{\mathrm{c} 2} \times c_{2}\left(\frac{8 \epsilon_{\circ}-3 \phi \times c_{2}}{12 \epsilon_{\circ}-4 \phi \times c_{2}}\right)\right]-\right. \\
& \left.\left[\mathrm{C}_{\mathrm{c} 1} \times c_{1}\left(\frac{8 \epsilon_{\mathrm{o}}-3 \phi \times c_{1}}{12 \epsilon_{\mathrm{o}}-4 \phi \times c_{1}}\right)\right]\right\} / \mathrm{C}_{\mathrm{c}}(3)
\end{aligned}
$$

An iterative algorithm is developed to predict the moment-curvature relations. The solution procedure is based on first assuming $\mathrm{c} 2$ and $\epsilon_{c \text { max }}$. The internal stresses and forces are then found based on a discretized model of the cross section. The validity of the assumed $c 2$ and $\epsilon_{c \max }$ is then checked using one of the following applicable force equilibrium equations:

$$
\begin{aligned}
& \mathrm{C}_{\mathrm{c}}+\mathrm{T}_{\mathrm{ps}}=0(4) \\
& \mathrm{C}_{\mathrm{c}}+\mathrm{T}_{\mathrm{ps}}+\mathrm{T}_{\mathrm{CFRP}}=0(5) \\
& \mathrm{C}_{\mathrm{c}}+\mathrm{T}_{\mathrm{ps}}+\mathrm{T}_{\mathrm{CFRP}}+\mathrm{C}_{\mathrm{CFRP}}=0(6)
\end{aligned}
$$

Equations 4, 5, and 6 correspond to the cross sections presented in Fig. 1 and 2(a), 1(b), and 1(c) respectively. Once the axial force equilibrium is satisfied, the internal resisting moment is determined by summing up the respective internal resisting forces multiplied by the applicable lever arms. This process provides one point on the moment-curvature relation for a given cross section. The iterative algorithm is repeated for different values of $c_{2}$ and $\epsilon_{c \max }$ to get a number of moment-curvature points to draw the moment-curvature curves shown in Fig. 4 and Fig. 5 until reaching the ultimate concrete strain of $0.003 \mathrm{in}$./in.

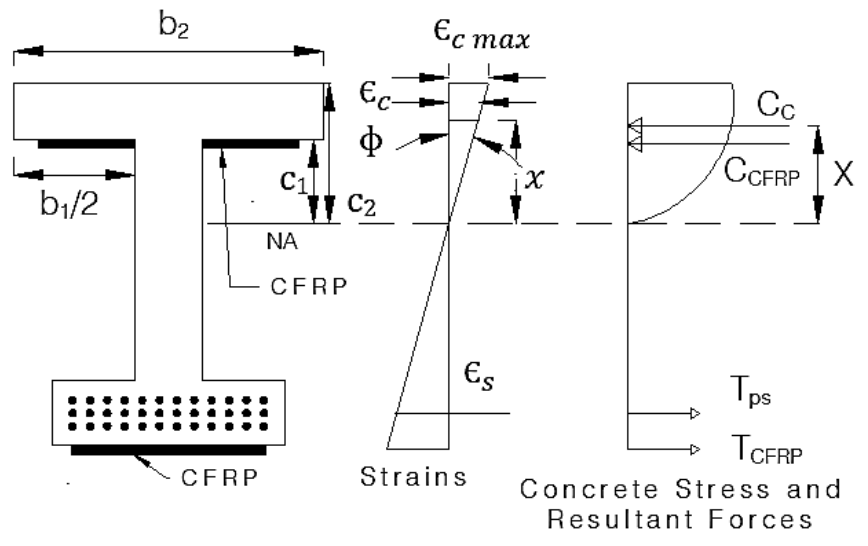

Fig. 3. Cross-Sectional strains, stresses and forces.

\section{NUMERICAL RESULTS}

The predicted moment-curvature relations for each of the three girder cross sections in Fig. 1 are presented in Fig. 4. For the cross section with ultimate concrete strength of 8000 psi and retrofitted in both tension and compression regions results in a 72 percent increase in the flexural strength. The cross section retrofitted only in the tension region gives a 51 percent increase in flexural strength. Changing concrete ultimate strength to 7,000 psi, 6,000 psi, and 5,000 psi for the cross section shown in Fig. 1(c) results in a flexural strength increase of 60,48 , and 36 percent, respectively.

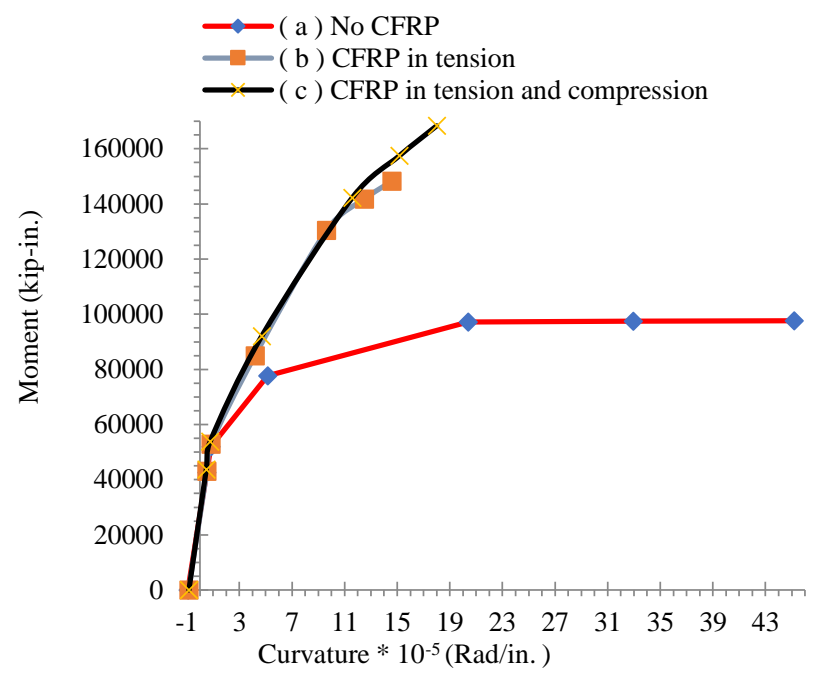

Fig. 4. Moment-curvature relations for the girder.

Fig. 5 shows the moment-curvature relations for the Ibeam retrofitting schemes shown in Fig. 2. The curves shown in these figures are terminated for the cross section with ultimate concrete strength of 8000 psi and when the maximum concrete strain in compression reaches 0.003 in./in. The limiting concrete strain therefore resulted in CFRP stresses well below its ultimate strength of $260 \mathrm{ksi}$. With CFRP retrofitting in the high-tension region only, a 46 percent increase in the moment capacity is observed. However, it is seen that a more effective retrofitting scheme results when CFRP is installed in both high tension and 
compression regions simultaneously, resulting in an increase in the moment capacity by 60 percent. Changing concrete ultimate strength to $7,000 \mathrm{psi}, 6,000 \mathrm{psi}$, and 5,000 psi for the cross section shown in Fig. 2(c) results in a flexural strength increase of 50, 39, and 26 percent, respectively.

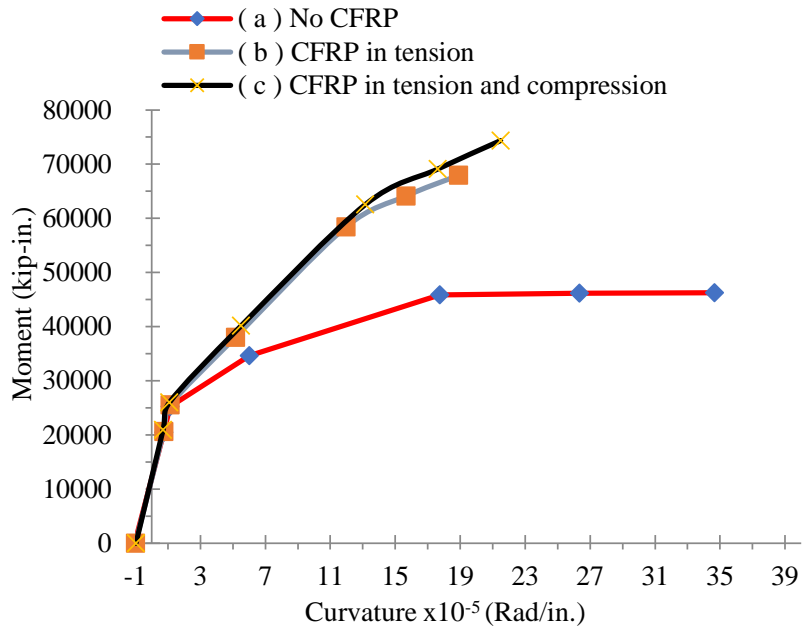

Fig. 5. Moment-curvature relations for the I-beam.

\section{PRACTICAL EXAMPLE}

For the bridge girder shown in Fig. 6 with a span of $40 \mathrm{ft}$, and a section as shown in Fig. 1(c), determine and compare the ultimate bending moment capacity both with and without CFRP retrofitting, and calculate $\mathrm{w}$ at collapse.

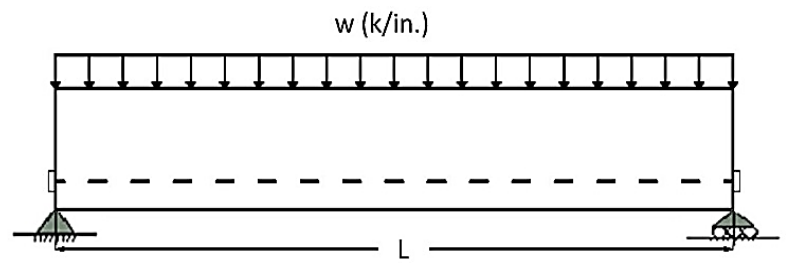

Fig. 6. Bridge girder example.

\section{Solution:}

From Fig. 4, the ultimate bending moment capacity of the cross-section shown in Figure 1(c) with and without CFRP retrofitting is, respectively, equal to 168,329 kip-in., and 97,642 kip-in. Thus, the percent increase is the ultimate bending moment capacity of the retrofitted beam is:

$$
\frac{168329}{97642} \times 100=72.4 \%
$$

Based on the maximum bending moment at the midspan of the beam in Figure 6, the value of $\mathrm{w}$ for the retrofitted beam at collapse is:

$$
\mathrm{w} \text { at collapse }=\frac{8 \times\left(\frac{168329}{12}\right)}{40^{2}}=70.14 \mathrm{kips} / \mathrm{ft}
$$

In comparison, the non-retrofitted girder will collapse at $70.14(0.724)=50.78 \mathrm{kips} / \mathrm{ft}$.

\section{CONCLUSION}

The following conclusions are drawn from the study of both non-retrofitted and CFRP retrofitted prestressed concrete beam cross sections:

1. Retrofitting the prestressed concrete beam cross section simultaneously in both tension and compression regions results in the largest gain in flexural strength.

2. The higher the concrete ultimate strength, the higher is the percentage of the beam cross-sectional flexural strength.

3. Although the non-retrofitted beam cross section is more ductile in nature, its ultimate flexural strength is substantially lower than the retrofitted one.

4. The initial 'elastic' portion of the moment-curvature relations for both non-retrofitted and retrofitted beam cross sections are practically the same, however, they are different in the materially nonlinear range.

5. When retrofitting is used simultaneously in both tension and compression regions, the concrete reaching its strain capacity in compression is delayed in comparison to that for the beam cross section retrofitted only in the tensile region.

6. The percentage of flexural strength increase in CFRP retrofitted girders is higher compared to CFRP retrofitted building I-beams.

\section{REFERENCES}

[1] Prince Engineering. (2017, September 25). Carbon Fiber used in Fiber Reinforced Plastic Available: http://www.build-onprince.com/carbon-fiber.html\#sthash.zXRHel78.dpbs.

[2] H. A. Hussein and Z. Razzaq, "CFRP Retrofitting Schemes for Prestressed Concrete Box Beamsfor Highway Bridges," Global Journal of Research In Engineering, 2017.

[3] H. A. Hussein and Z. Razzaq, "Prestressed Concrete Inverted Tee Beams With CFRP for Building Structures," Global Journal of Research In Engineering, 2017.

[4] O. Chaallal, M.-J. Nollet, and D. Perraton, "Strengthening of reinforced concrete beams with externally bonded fiber-reinforcedplastic plates: design guidelines for shear and flexure," Canadian Journal of Civil Engineering, vol. 25, no. 4, pp. 692-704, 1998.

[5] K. Ryngier and Ł. Zdanowicz, "Prestressing concrete structures with CFRP composite tendons," Engineering Transactions, vol. 63, no. 4, pp. 407-420, 2015.

[6] H. Yapa and J. Lees, "Rectangular Reinforced Concrete Beams Strengthened with CFRP Straps," Journal of Composites for Construction, 2013.

[7] H. A. Hussein, "Effective CFRP Retrofitting Schemes for Prestressed Concrete Beams," Old Dominion University, 2014.

[8] T. Y. Lin and N. H. Burns, "Design of prestressed concrete structures," 1981.

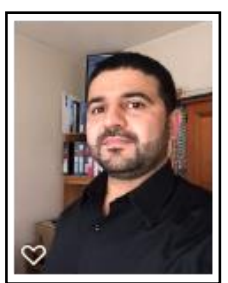

Herish A. Hussein is a Ph.D. candidate at Old Dominion University, Norfolk, VA, USA. He was born in the Iraqi Kurdistan, city of Sulaimany, on Dec. 15, 1984. Herish has bachelor's degree in Civil/Geotechnical Engineering from Koya university in Iraq, city of Koya (graduated in July 2009), and he has his master's degree majoring in structural engineering from Old Dominion University (graduated in Dec. 2014). Herish's field of study is structural engineering. 